\title{
Bilateral Origin of the Testicular Arteries from the Lower Polar Accessory Renal Arteries
}

\author{
Origen Bilateral de las Arterias Testiculares desde las \\ Arterias Renales Polares Inferiores Accesorias
}

Eleni Panagouli; Evangelos Lolis \& Dionysios Venieratos

\begin{abstract}
PANAGOULI, E.; LOLIS, E. \& VENIERATOS, D. Bilateral origin of the testicular arteries from the lower polar accessory renal arteries. Int. J. Morphol., 30(4):1316-1320, 2012.

SUMMARY: The gonadal arteries (testicular or ovarian arteries) emerge normally from the lateral aspect of the abdominal aorta, a little inferior to the renal arteries. Several other sites of origin of these arteries have been recorded with the renal and accessory renal arteries being the most common. In the present case report, the testicular arteries originated from the lower polar accessory renal arteries in both sides. The testicular veins followed had the usual origin and course, while an accessory renal vein was observed only in the right side. These anomalies were combined with an abnormal left ureter exiting from the lower pole of the kidney. Only one male cadaver among 77 adult human cadavers of Caucasian origin presented this set of variations (frequency: $\leq 1.3 \%$ ). Variations of renal and gonadal vessels are important, as their presence could result in vascular injury of any accessory or aberrant vessel if the surgeon does not identify them.
\end{abstract}

KEY WORDS: Gonadal arteries; Kidney; Ureter; Abdominal aorta.

\section{INTRODUCTION}

The gonadal arteries (GA), described as one of the paired branches of the abdominal aorta (AA), emerge normally a little inferior to the renal arteries (Standring et al., 2008). Then, they course inferiorlaterally under the parietal peritoneum before the psoas muscle and terminate in the gonads, which they supply (Standring et al.). According to the gender, they are named as testicular or ovarian arteries (TA, OA).

In addition to the normal pattern, several other sites of origin of the GAs have been described; among them the renal, accessory renal and suprarenal arteries are most commonly mentioned (Lippert \& Pabst 1985; Asala et al., 2001; Cicekcibasi et al., 2002; Bergman et al., 2006; Petru et al., 2007; Shoja et al., 2007; Pai et al., 2008) and more rarely the lumbar, common or internal iliac and superior epigastric arteries (Lippert \& Pabst; Bergman et al.; Paraskevas et al., 2011).

The presence of one or more accessory renal arteries (ARA) at one or both sides seems to be the most common anatomic variation of the renal arteries (RA) (Tarzamni et al., 2008) with an incidence, which ranges from $8.7 \%$ to $75.7 \%$ (Satyapal et al., 2001). They are most commonly found unilaterally rather than bilaterally (approximately $30 \%$ and $10 \%$ of the observed cases respectively (Spring, 1979; Tarzamni et al.).

The ureters are two muscular tubes which superiorly continue as the funnel shaped renal pelvis and inferiorly they enter the urinary bladder (Standring et al.). In most of the cases, the renal pelvis lies in the middle of the medial edge of the kidney, in close vicinity with the renal vessels, thus forming the renal hilum. Several variations of the ureters have been described such as absence, duplication or multiple ureters and ectopic ureters (Bergman et al.).

In the present case report we describe an anomalous origin of both TAs from the lower polar ARAs, combined with a right accessory renal vein (ARV) and a left ureter abnormally exiting from the lower pole of the kidney. 


\section{MATERIAL AND METHOD}

The anatomy of the branches of the AA was carefully examined in 77 embalmed adult human cadavers of Caucasian (Hellenic) origin (40 male and 37 female). The age of the specimens ranged between 39 and 98 years (average age 75.6 years, $\mathrm{SD}= \pm 11.674, \mathrm{SE}=1.385$ ). All the cadavers derived from body donation with informed consent (McHanwell et al., 2008), written and signed (with signature authentication) by the donator himself. The dissection was performed for educational purposes at the Anatomy Department of the Medical School of the University of Athens.

In every cadaver the dissection was made with special care to reveal the branches of the AA. All the observed variations of these vessels were recorded. If it was considered necessary to record distances between vessels, the center of the origin of each vessel was taken as reference point. The distances were measured using callipers.

\section{RESULTS}

Among all the studied cadavers, only one presented bilateral variations of both the RAs and TAs $(1.3 \%, 1 / 77)$. During dissection of the abdomen in a male Caucasian cadaver (deceased at the age of 79), the following variations were discovered:

Right side. The right kidney was supplied by two arteries. The first one entered the renal hilum and was considered as the main RA, following the normal course and branching (Figs. 1 and 2). The second one originated from the anterior surface of the AA, passing in front of the inferior vena cava and, after $7.7 \mathrm{~cm}$, it entered the lower pole of the kidney (Figs. 1 and 2). Thus, this supplementary artery was considered as a lower polar ARA. The right TA rose from this artery, $2.5 \mathrm{~cm}$ after its origin (Figs. 1 and 2).

The right renal vein (RV) accompanied the right main RA, while an ARV existed which entered the lower pole over the right lower polar ARA (Fig. 2). The right testicular vein (TV) did not present any deviations from the normal.

Left side. The left kidney was discovered to have similar arterial supply as the right one, namely a main RA and a lower polar ARA. The left lower polar ARA emerged from the left lateral side of the AA, just below the main one and was smaller than its right counterpart, with a length of $6.8 \mathrm{~cm}$ (Figs. 1 and 2). Four (4.0) cm after its origin it gave rise to the left TA. Both the left RV and TV had the normal origin and course. Noticeably, this lower polar ARA passed in front of the RV. Surprisingly enough, the left ureter left the kidney from its lower pole (Figs. 1 and 2). It coursed downwards, passed posterior to the left TA and TV and anterior to the left common iliac artery (Fig. 1).

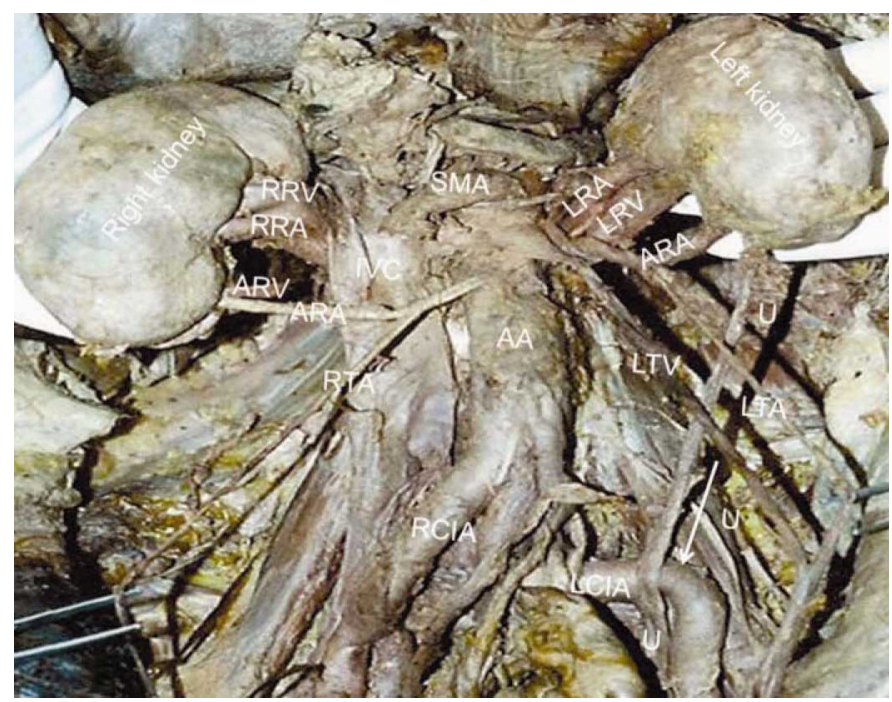

Fig. 1. Left and right testicular arteries (LTA, RTA) originating from left and right accessory renal arteries (ARA). RRA: right renal artery, RRV: right renal vein, LRA: left renal artery, LRV: left renal vein, ARV: accessory renal vein (cut), RCIA: right common iliac artery, LCIA: left common iliac artery, AA: abdominal aorta, IVC: inferior vena cava, LTV: left testicular vein, SMA: superior mesenteric artery (dissected) and U: ureter.

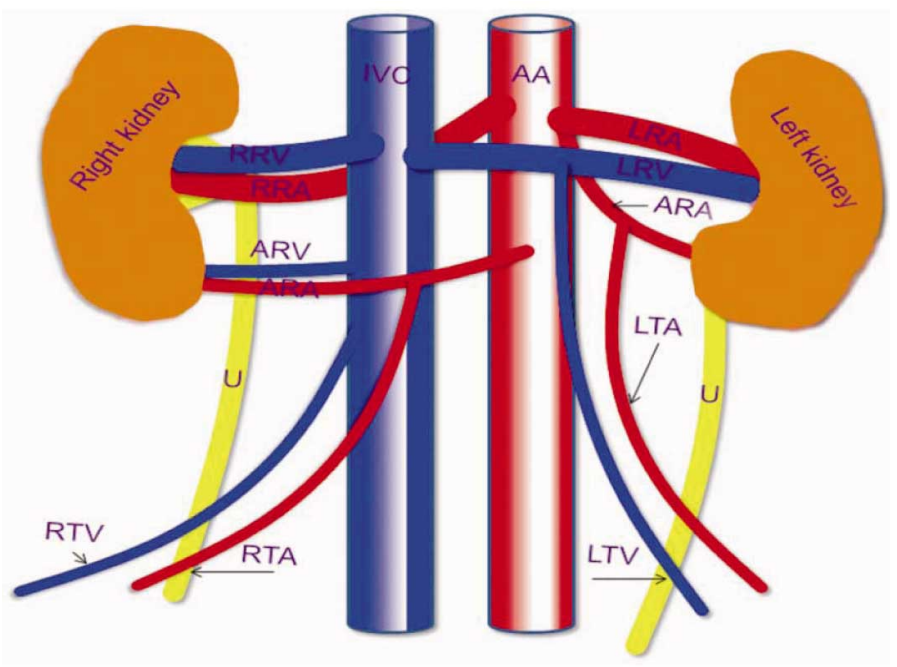

Fig. 2. Schematic view of the described variations. RTA: right testicular artery, LTA: left testicular artery, ARA: accessory renal artery RRA: right renal artery, RRV: right renal vein, LRA: left renal artery, LRV: left renal vein, ARV: accessory renal vein, AA: abdominal aorta, IVC: inferior vena cava, LTV: left testicular vein, RTV: right testicular vein and U: ureter. 


\section{DISCUSSION}

The variations of GAs concern deviations in their origin, course and number (Paraskevas et al.). They may be unilaterally or bilaterally doubled, tripled, or even quadrupled (Bergman et al.), and they may rise from a common stem with the suprarenal arteries (1 in 26 suprarenal glands, Adachi, 1928). According to classical anatomical textbooks (Lippert \& Pabst), the normal pattern is followed in the $83 \%$ of the cases, while several studies report anomalies in their origin with an incidence, which range from $4.7 \%$ (7/150, Asala et al.) to $75 \%$ (12/16, Petru et al.). More specifically, the gonadal arteries are reported to rise from the main renal arteries with a frequency, which varies from $1.47 \%(1 / 68$ sides, Pai et al.) to $17 \%$ (Lippert \& Pabst), while their origin from an accessory renal artery ranges from 5.5\% (5/90, Cicekcibasi et al.) to $31.25 \%$ (5/16, Petru et al.). The latter is recorded to occur bilaterally only in the $1.1 \%$ of the (total) cases (1/90, Cicekcibasi et al.).

The TAs tend to present anomalous origin more often (15.5\% - 14/90, Cicekcibasi et al.), than the OAs (2.2\%, 2 / 90, Cicekcibasi et al.). On the other hand, variations of the gonadal veins seem to be even more frequent $(21.3 \%$ - 32/ 150, Asala et al.).

In the present report the TAs rose bilaterally from ARAs which coursed both to the inferior pole of the kidney to which they belong (lower polar ARA). The TV followed the normal origin and course, as well as the main RA. A lower polar ARV existed only in the right side. This set of arterial variations (without taking into account the left ureter) was observed in the $1.3 \%$ of our series (1/77 cadavers).

Cicekcibasi et al., collected their data from spontaneously aborted fetuses and classified the discovered variations in the origin of the GAs into four types as follows: Type I: origin from the suprarenal artery (4.4\% in the right and $1.1 \%$ in the left side); Type II: origin from the RA $(2.2 \%$ in the right and $3.3 \%$ in the left side); Type III: high-positional origin from the AA, in the level of the RA $3.3 \%$ in the right and $1.1 \%$ in the left side); Type IV: duplication of the TA $(3.3 \%)$. It should be mentioned that in type II the GA always emerged from the inferior polar arteries and not from the main ones. Bilateral variations were observed only in the TAs (not the OAs) in 4.4\% (4/90 cases).

Pai et al., according to the findings of their study, described the following variations: In the so called, variation 1 , the TA was described as a branch of the inferior polar artery (5/68-7.4\%, 3/34 right sides and 2/34 left sides). In variation 2 the TA emerged from the main RA on one right side (1/68-1.47\%). In variation 3 occurred a high origin of the TA and in variation 4 a double TA. All these variations were reported to coexist with multiple renal vessels, either arteries or veins.

The most common variation in the site of origin of the GAs seems to be their branching from ARAs and especially from the lower polar ones, as in our case. In the study of Shoja et al., the GA emerged from the inferior polar artery in $5 / 98$ cases in the right and in $2 / 98$ cases in the left side, while origin from the upper polar artery was observed only in two cases in the right side.

The variation presented in this report belongs in type II of Cicekcibasi et al., which was observed in both sides only in one case (1/90 fetuses, $1.1 \%)$. The origin of both TAs from lower polar ARA is rarely mentioned in the available literature. Sylvia et al., (2009) reported a case with bilateral polar ARAs, but only the left one gave as a branch the TA, while the right one rose in fact from the main RA. Singh et al., (1998) described a case where the right (and quite probably the left as well) OA stemmed from lower polar ARA.

Both kidneys and gonads develop during embryonic life from the intermediate mesoderm of the mesonephric crest (Cicekcibasi et al.). Their blood supply derives also from a common source, namely the lateral mesonephric branches of the dorsal aorta (Ozan et al., 1995; Cicekcibasi et al.). The mesonephric arteries can be divided in cranial, middle and caudal groups. The GAs most commonly arise from the caudal group (Cicekcibasi et al.), while their persistence may lead to ARAs. As the embryo grows, the kidney follows an ascending course, whereas the gonads descend. By the time the two organs cross, the testis receives two main branches the one above and the other below the kidney. The lower branch usually atrophies when the organs reach their final position (Ravery et al., 1993). Anomalies during the degeneration of these primitive arteries might lead to variations. Cicekcibasi et al., suggested that anomalous arteries as the one described in our case may originate from the middle part of the mesonephric arteries.

The ureter is the cylindrical continuation of the funnel-shaped renal pelvis. The transition point is usually extra-hilar and normally lies in the lower part of the medial border of the kidney. Rarely, the entire renal pelvis is found to lie inside the kidney (Standring et al.). If this rare situation exists in combination with a slowly developing and therefore relatively short ureter, they may lead to the variation observed 
in the case described: Namely a ureter originating from the lower pole of the kidney.

Variations of renal and gonadal vessels are important for retroperitoneal space surgery. The surgeon should be aware of the possible variations in the vascular supply of the kidney when performing nephrectomy in order to identify and ligate any aberrant vessel and not to inadvertently injure or avulse it during dissection. In partial nephrectomy, when it is indicated for tumor or for trauma, the regional vascular supply of the kidney must be taken into account.

In kidney retrieval for transplantation, any supernumerary vessel must be dissected carefully and preserved. The perfusion of the kidney must be done through all its arteries. In addition, during kidney implantation every vessel must be anastomosed to the recipient's iliac vessels.

In aortic surgery, dissection of the AA could result in vascular injury of any accessory renal vessel if the surgeon does not identify them. A troublesome bleeding may then occur. An aberrant GA could be avulsed at its origin from the ARA during dissection of the later because its presence may not be anticipated. Resection of retroperitoneal tumors and sarcomas could also result in bleeding if aberrant renal vessels or variations of GA origin are present, especially if the tumor is large.

PANAGOULI, E.; LOLIS, E. \& VENIERATOS, D. Origen bilateral de las arterias testiculares desde las arterias renales polares inferiores accesorias. Int. J. Morphol., 30(4):1316-1320, 2012.

RESUMEN: Las arterias gonadales (testiculares o ováricas) se originan normalmente de la parte lateral de la parte abdominal de la aorta, distal a las arterias renales. Se han registrado otros lugares de origen de estas arterias, entre ellos, los más comunes en las arterias renales y renales accesorias. En el presente caso, las arterias testiculares se originaron bilateralmente desde las arterias renales polares inferiores accesorias. Las venas testiculares siguieron el origen y curso habitual, mientras que una vena renal accesoria sólo se observó en el lado derecho. Estas anomalías se combinaron con un uréter izquierdo anormal que salía desde el polo inferior del riñón. Sólo un cadáver de sexo masculino, de origen caucásico, entre los 77 cadáveres humanos adultos, presentaba este conjunto de variaciones (frecuencia: $\leq 1,3 \%$ ). Las variaciones de los vasos renales y gonadales son importantes. Su presencia, si el cirujano no los identifica, puede resultar en lesiones vasculares de algún vaso accesorio o aberrante.

PALABRAS CLAVE: Arterias gonadales; Riñon; Uréter; Parte abdominal de la aorta.

\section{REFERENCES}

Adachi, B. Das Arteriensystem der Japaner II. Kyoto und Tokyo, Maruzen Publishing Co., 1928.

Asala, S.; Chaudhary, S. C.; Masumbuko-Kahamba, N. \& Bidmos, M. Anatomical variations in the human testicular blood vessels. Ann. Anat., 183(6):545-9, 2001.

Bergman, R. A.; Afifi, A. K. \& Miyauchi, R. Illustrated Encyclopedia of Human Anatomic Variation. 2006. Available in: http:// www.anatomyatlases.org/AnatomicVariants/AnatomyHP.shtml

Cicekcibasi, A. E.; Salbacak, A.; Seker, M.; Ziylan, T.; Büyükmumcu, M. \& Uysal, I. I. The origin of gonadal arteries in human fetuses: anatomical variations. Ann. Anat., 184(3):275-9, 2002.

Lippert, H. \& Pabst, R. Arterial variations in man. Classification and frequency. Munich, J. F. Bergmann, 1985.

McHanwell, S.; Brenner, E.; Chirculescu, A. R. M.; Drukker, J.; van Mameren, H.; Mazzotti, G.; Pais, D.; Paulsen, F.; Plaisant, O.; Caillaud, M. M.; Laforet, E.; Riedere, B. M.; Sanudo, J. R.; Bueno-Lopez, J. L.; Donate-Oliver, F.; Sprumont, P.;
Teofilovski-Parapid, G. \& Moxham, B. J. The legal and ethical framework governing Body Donation in Europe - A review of current practice and recommendations for good practice. Eur. J. Anat., 12(1):1-24, 2008.

Ozan, H.; Gümüsalan, Y.; Onderoglu, S. \& Simsek, C. High origin of gonadal arteries associated with other variations. Ann. Anat., 177(2):156-60, 1995.

Pai, M. M.; Vadgaonkar, R.; Rai, R.; Nayak, S. R.; Jiji, P. J.; Ranade, A.; Prabhu, L. V. \& Madhyastha, S. A cadaveric study of the testicular artery in the South Indian population. Singapore Med. J., 49(7):551-5, 2008.

Paraskevas, G. K.; Ioannidis, O.; Raikos, A.; Papaziogas, B.; Natsis, K.; Spyridakis, I. \& Kitsoulis, P. High origin of a testicular artery: a case report and review of the literature. J. Med. Case Rep., $5: 75,2011$.

Petru, B.; Elena, S.; Dan, I. \& Constantin, D. The morphology and the surgical importance of the gonadal arteries originating from the renal artery. Surg. Radiol. Anat., 29(5):367-71, 2007. 
Ravery, V.; Cussenot, O.; Desgrandchamps, F.; Teillac, P.; MartinBouyer, Y.; Lassau, J. P. \& Le Duc, A. Variations in arterial blood supply and the risk of hemorrhage during percutaneous treatment of lesions of the pelviureteral junction obstruction: report of a case of testicular artery arising from an inferior polar renal artery. Surg. Radiol. Anat., 15(4):355-9, 1993.

Satyapal, K. S.; Haffejee, A. A.; Singh, B.; Ramsaroop, L.; Robbs, J. V. \& Kalideen, J. M. Additional renal arteries: incidence and morphometry. Surg. Radiol. Anat., 23(1):33-8, 2001.

Shoja, M. M.; Tubbs, R. S.; Shakeri, A. B. \& Oakes, W. J. Origins of the gonadal artery: embryologic implications. Clin. Anat., 20(4):428-32, 2007.

Singh, G.; Ng, Y. K. \& Bay, B. H. Bilateral accessory renal arteries associated with some anomalies of the ovarian arteries: a case study. Clin. Anat., 11(6):417-20, 1998.

Spring, D. B.; Salvatierra, O. Jr.; Palubinskas, A. J.; Amend, W. J. Jr.; Vincenti, F. G. \& Feduska, N. J. Results and significance of angiography in potential kidney donors. Radiology, 133(1):45-7, 1979.

Standring, S.; Borley, N. R.; Collins, P.; Crossman, A. R.; Gatzoulis, M. A., Healy, J. C.; Johnson, D.; Mahadevan, V.; Newell, R. L. M. \& Wigley, C. B. Gray's anatomy. The anatomical basis of clinical practice. Edinburgh, Elsevier, 2008.

Sylvia, S.; Kakarlapudi, S. V.; Vollala, V. R.; Potu, B. K.; Jetti, R.; Bolla, S. R.; Rao, M. \& Pamidi, N. Bilateral variant testicular arteries with double renal arteries. Cases J., 2(1):114, 2009.

Tarzamni, M. K.; Nezami, N.; Rashid, R. J.; Argani, H.; Hajealioghli, P. \& Ghorashi, S. Anatomical differences in the right and left renal arterial patterns. Folia Morphol. (Warsz), 67(2):104-10, 2008.

\section{Correspondence to: Eleni Panagouli Department of Anatomy Medical School University of Athens Mikras Asias str. 75, 11627 Athens \\ GREECE}

Tel: 302107462394

Fax: 302107462398

Email: eleni72000@yahoo.gr

Received: 28-09-2011

Accepted: 06-03-2012 